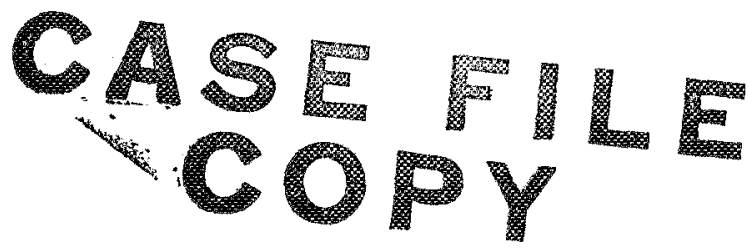

\title{
IMPACT RESISTANCE OF UNIDIRECTIONAL FIBER COMPOSITES
}

by C. C. Chamis, M. P. Hanson, and T. T. Serafini

Lewis Research Center

Cleveland, Ohio

TECHNICAL PAPER proposed for presentation at

Second Conference on Composite Materials: Testing and Design

sponsored by the American Society for Testing and Materials

Anaheim, California, April 20-22, 1971 
IMPACT RESISTANCE OF UNIDIRECTIONAL FIBER COMPOSITES

$$
\begin{gathered}
\text { C. C. Chamis, }{ }^{1} \text { M. P. Hanson, }{ }^{1} \text { and T. T. Serafini } \\
\text { National Aeronautics and Space Administration } \\
\text { Lewis Research Center } \\
\text { Cleveland, Ohio }
\end{gathered}
$$

ABSTRACT: Composite micromechanics and macromechanics and the miniature Izod impact test are used to investigate the impact resistance of unidirectional composites. Several composite systems are examined both theoretically and experimenta11y. The composites are classified theoretically relative to their impact resistance for longitudinal, transverse and shear modes, Experimental results are reported only for Izod impact with the fibers either parallel or transverse to the cantilever longitudinal axis. Impact resistance design criteria which evolved during this investigation are used to design hybrid composites with improved impact resistance. This is illustrated theoretically and demonstrated experimentally. The results show that in-situ fiber and matrix elongationto-fracture, matrix modulus, fabrication process, fiber and void volume ratios and microresidual stresses are variables which affect the impact resistance. The ranking of composite impact resistance on the basis of measured and predicted results was in excellent agreement. KEY WORDS: fiber composites, hybrid composites, stress analysis, structural analysis, design, impact, micromechanics, micro-residual stress, debonding, delamination, Izod impact

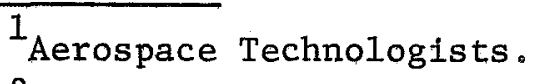

${ }^{2}$ Section Head. 
NOMENCLATURE

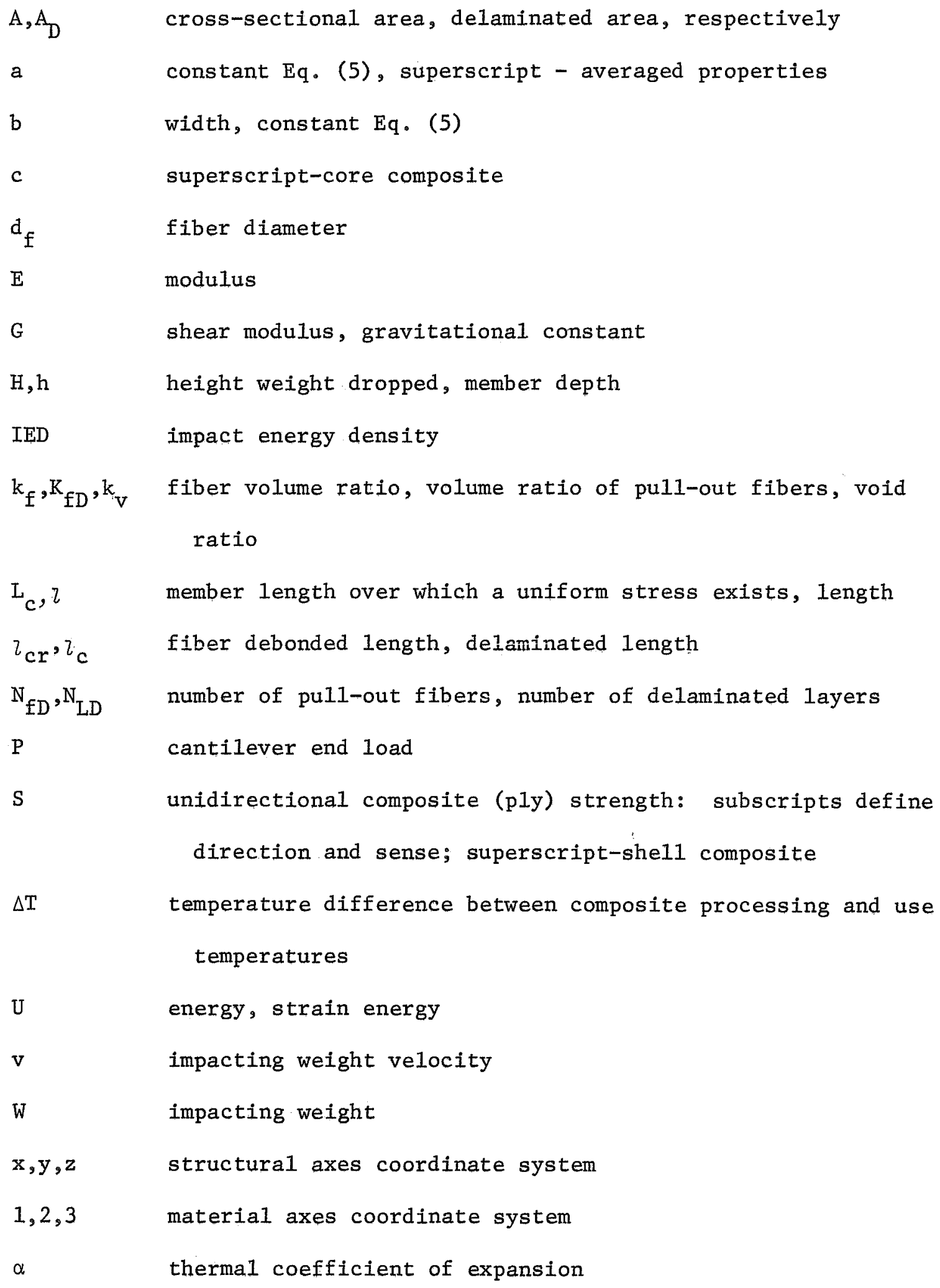




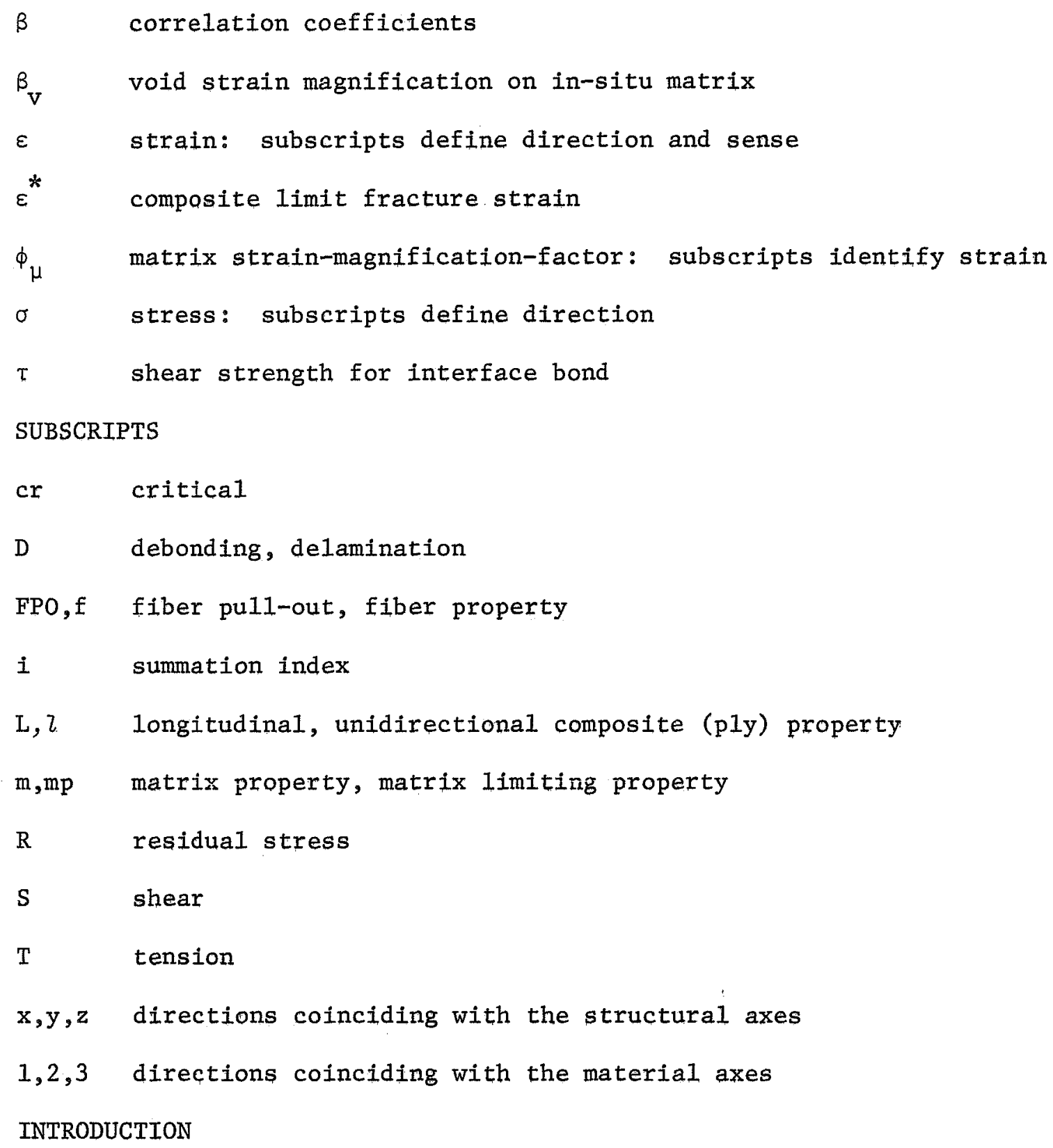

An important design aspect of fiber composite structural components is their impact resistance. Some basic work on impact resistance and on other closely related properties of these materials has been reported in the 1iterature. See for example references [1-5]. ${ }^{3}$ However, the understanding of impact resistance of fiber composites has not advanced

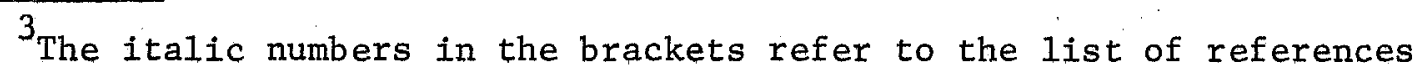
appended to this paper. 
to the point where components can be designed for impact using conventional design procedures.

To obtain an insight into the impact resistance of structural components made from fiber composites we begin by examining their physical makeup. The components considered herein are made by laminating several plies; the ply is itself a unidirectional composite, A better understanding of component impact resistance can then be obtained by investigating the impact resistance of individual plies, multi-ply unidirectional composites, the interply matrix layers, and the constituent material properties and fabrication processing variables. This paper deals with such an investigation. The investigation is limited to grosstype-impact (sufficiently long impact contact times so that the entire component resists the impacting force) and to unidirectional composites which exhibit a linear static stress-strain relationship to fracture.

The objectives of the investigation are to obtain a better understanding of impact resistance through elementary theoretical considerations and simple experiments. The experiments are of a qualitative nature and serve as a means to rank the composites. The following factors are examined: interpretation of impact resistance in terms of the energy under the static stress-strain diagram; relationship of this energy to constituent material properties and fabrication processing variables; identification of prevalent failure modes; identification of constituent material properties which have a strong influence on impact resistance; construction of design criteria for improving impact resistance; and, classification of several available fiber composites on an impact resistance scale. 
The theoretical expressions for predicting impact resistance are covered in the section "Theoretical Investigation." Here, impact resistance associated with single or combined fracture modes is presented and discussed. Design concepts using hybrid composites are also covered. The detailed derivations are omitted here but they are given in [6]. The experimental investigation is described in the section "Experimental Investigation." In this section, the constituent materials, fabrication process; test specimens and test methods are described. The experimental results are also discussed in this section. Both theoretical and experimental results are presented in tabular and graphical forms and can serve as an aid in design. THEORETICAL INVESTIGATION

In general advanced unidirectional fiber composites exhibit linear stress-strain behavior. (Fig. 1). Linear stress-strain relationships are also retained at high rates of loadings [7]. These linear stress strain relationships and composite micromechanics $[8,9]$ form the basis of the theoretical development for computing the impact resistance.

The impact loadings which are considered here, are illustrated in Fig. 2. As can be seen in this figure the impact loadings are either along the material axis of the composite (1ongitudinal, transverse or shear) or at the free end of a cantilever. Longitudinal Impact Reșistance

Longitudinal impact loading can result in either of two modes of fracture. These are: (1) cleavage - the fracture surface consists of fractured fibers and matrix which lie approximately in the same plane. (2) Cleavage with fiber pullout - the fracture surface consists of 
fractured fibers in combination with debonding and fiber pu11-out. In the latter case not all of the fracture surfaces of the fibers lie on the same plane. Both of these fracture modes are extensively discussed in $[3,4,10]$.

Impact-Induced Cleavage Fracture

The equation describing cleavage failure due to impact is obtained by determining the strain energy density. It is shown experimentally in [11] that the strain energy density correlates with Izod impact. For longitudinal impact, Fig. 1a, this is simply

$$
\mathrm{U}=\frac{1}{2} \varepsilon_{Z 11 \mathrm{~T}}^{*} \mathrm{~S} Z 11 \mathrm{~T}
$$

or

$$
\mathrm{U}=\left(\mathrm{s}_{211 \mathrm{~T}}^{2} / 2 \mathrm{E}_{211}\right) \mathrm{V}
$$

where $U$ is the strain energy, $\varepsilon^{*}$ is the fracture strain, $S$ is the fracture strength, $E$ is the modulus, and $V$ is the volume: The súbscript group ( $211 \mathrm{~T}$ ) is defined ás follows: ( 2 ) refexs to unidirectional properties (II) identify the fiber direction and load direction in that order; (T) identifies the sense of the stress. Using composite micromechanics [9] two equations can be derived for $\mathrm{S}_{211 \mathrm{~T}}$ depending on whether the fibers or the matrix offer the primary resistance to fracture. The derivations are given in [6]. Here we give only the final equations. The impact resistance density (IED) of composites with $E_{f} / E_{m}$ ratio greater than 20 is approximated by

$$
I E D=\frac{\left(1-k_{V}\right) k_{f} \beta_{f T}^{2} s_{f T}^{2}}{2 E_{f}}
$$

with an approximation error of less than 5 percent. The undefined vari- 
ables in Eq. (3) are as follows: $k_{v}$ and $k_{f}$ denote void and fiber volume ratios, respectively; $\beta_{f T}$ represents the in-situ fiber strength efficiency which reflects the fabrication process; the subscript $f$ refers to fiber property. The important points to be noted in Eq. (3) are the quadratic dependence of the strain energy density on the fiber strength $S_{f T}^{2}$ and the fabrication process variable $\beta_{f T}^{2}$. For a high impact resistance composite Eq. (3) imposes the following requirements: a high strength, low modulus fiber, approximately 100 percent fiber properties translation efficiency, high fiber volume ratio and low void volume ratio. Three additional points to be noted here are: (1) The dependence of the strain energy density and therefore impact resistance on $\mathrm{S}_{\mathrm{fT}} / \mathrm{E}_{\mathrm{f}}$ and $\mathrm{k}_{\mathrm{f}}$ has been clearly demonstrated in $[12,13]$. (2) The contribution of $\left(1-k_{v}\right) \beta_{f T}^{2}$ is contradictory to the results predicted by the debonding and fiber pul1-out mechanism. See section on debonding and fiber pul1-out and also [3 and 4]. (3) Equation (3) is a simple and convenient means to rank fiber composites for longitudinal impact resistance.

A graphical representation of Eq. (3) for various available composites is shown in Fig. 3, where the strain energy density is plotted as a function of $\mathrm{S}_{\mathrm{fT}} / \mathrm{E}_{\mathrm{f}}$ (fiber-strength to fiber-modulus ratio) which equals in-situ fiber elongation-to-fracture. These same composites have been ranked according to Eq. (3) in Table 1. Note in Table 1 three relatively new fibers have been listed. These are Thorne1-400, HMOF (a high modulus organic fiber) and UARL-344 Glass [14].

Rank comparisons of results reported in the literature with those predicted by Eq. (3) are shown in Table 2 for notched Charpy impact, in 
Table 3 for fracture toughness, and in Table 4 for energy-absorbed-tofailure at cryogenic temperatures. As can be seen in these tables, the ranking comparisons are in excellent agreement.

Effects of Micro-Residual Stresses on Impact Resistance

The contribution of the matrix to impact resistance is not negligible in composites with a strong and stiff matrix and having good interface bond. These types of composites usually have $E_{f} / E_{m}<10$, which is typical for fiber/metallic matrix composites.

The governing equation for the impact energy density for this case is given by

$$
I E D=a E_{\tau 11}\left[s_{m T}-b \frac{k_{f}}{E_{l 11}}\right]^{2}
$$

where

$$
\left.\begin{array}{l}
a=\frac{1}{2} E_{m}^{2} \\
b=\Delta T\left(\alpha_{f}-\alpha_{m}\right) E_{f} E_{m}
\end{array}\right\}
$$

The subscripts $Z, f$, and $m$ denote $p l y$, fiber, and matrix properties, respectively; $\alpha$ is the thermal coefficient of expansion and $\Delta T$ is the difference between the composite processing and use temperatures.

One very important point to be noted is Eqs. (4) and (5) is that the strain energy density depends significantly on the micro-residual stress. The micro-residual stress is represented by the parameter $b$ in Eq. (5), This dependence has not been reported previously in the literature. It is suspected that the presence of micro-residual stress in the matrix produced some of the trends reported in [3 and 15]. However, the authors of these references did not attribute the decrease in 
fracture energy to this phenomenon.

The dependence of the strain energy density and therefore the impact resistance on the micro-residual stress is illustrated in Fig. 4 for a boron-silicon carbide coated titanium system. Two sets of curves are plotted in this figure. One set is for matrix-controlled failure with and without residual stress. The other set is for fiber-controlled failure with and without residual stress. This second set was obtained from Eqs. (4) and (5) by interchanging the subscript $f$ with $m$.

The important point to be noted in Fig. 4 is that impact resistance, or fracture toughness, is very sensitive to the presence of microresidual stresses. Therefore, interpretation of experimental results from composites with $E_{f} / E_{m}<10$ must take the micro-residual stress into account.

Longitudinal impact loadings resulting in partial cleavage failure with debonding and fiber pull-out is a combined fracture mode. This type of mode will follow the description of the single modes. Transverse Impact Resistance

Transverse impact loadings of unidirectional composites (Fig, 2b) result in brittle fractures. The amount of energy absorbed to fracture during transverse impact is referred to as the transverse impact resistance. The strain energy divided by the volume of the material is referred to as the IED. This impact energy density as measured under the transverse stress-strain curve is shown in Fig. Ib. The governing equation is derived from the stress-strain diagram in Fig. $1 \mathrm{~b}$ and the micromechanics relations of [9]. The governing equation for the transverse impact energy density is given by 


$$
I E D=\frac{1}{2}\left(\beta_{22 \mathrm{~T}} \frac{\varepsilon_{\mathrm{mp} T}}{\beta_{\mathrm{v}} \phi_{\mu 22}}\right)^{2} \mathrm{E}_{222}
$$

The variables in Eq. (6) are as follows: $\beta_{22 \mathrm{~T}}$ is the correlation coefficient reflecting the fabrication process; $\varepsilon_{\mathrm{mpT}}$ is the maximum transverse strain that the in-situ matrix will experience when the composite is loaded in the transverse direction; $\beta_{\mathrm{v}}$ is the void magnification of the transverse matrix strain; $\phi_{\mu 22}$ is the matrix transverșe-strainmagnification factor; and $\mathrm{E}_{222}$ is the transverse composite modulus. There are several important points to be observed in Eq. (6). (1) The transverse impact resistance is a complex function of the fabrication process, material properties, and composite properties. (2) The degree of bond at the interface is reflected by $\beta_{22 T}$, the poorer the interface bond the smaller the value for this coefficient. (3) Increases in either void or fiber content or both have inverse square effects on the transverse impact resistance. These effects result in more brittle composite behavior. (4) The impact resistance increases linearly with the transverse modulus. (5) The impact resistance increases as the square of the in-situ matrix-fracture-strain.

It is important to note that the in-situ matrix-fracture strain is not the failure strain of the bulk matrix material. For nonmetallic matrixes the former is a small fraction of the latter [9]. The difference between in-situ and bulk matrix-fracture-strain is not widely recognized. As a result, efforts to correlate theory with experiment and to develop matrix materials which would result in improved composite properties have usually failed. However both of these disparities can be remedied with suitable micromechanics models and appropriate experi- 
ments [16].

The graphical representation of Eq. (6) for typical fiber composites is shown in Fig. 5. In this figure the impact energy density has been plotted as a function of fiber volume ratio. Three important points to be noted in Fig. 5 are: (1) The impact resistance of graphite fiber/ epoxy is insensitive to fiber volume ratio. (2) However, boron and glass fiber/epoxy composites become quite brittle at high fiber volime ratios (greater than 0.65$)$. (3) Al1 fiber/nonmetallic composites have approximately the same impact resistance at about 0.50 fiber volume ratio.

The variation of the impact resistance as a function of matrix modulus is shown in Table 5 for Modmor-I/epoxy composite. As can be seen in this table, the impact resistance increases very rapidly with increasing matrix modulus. There are two reasons for this rapid increase: (1) The matrix-strain-magnification factor $\phi_{\mu 22}$ decreases rapidly while the composite transverse modulus $\left(E_{Z_{22}}\right)$ increases (Table 5). (2) The fiber is anisotropic, that is, the transverse fiber modulus is about 0.7 to $1.4 \times 10^{6} \mathrm{~N} / \mathrm{cm}^{2}$ ( 1 to $2 \times 10^{6} \mathrm{psi}$ ). Shear Impact Resistance

Shear impact loadings of unidirectional composite (Fig. 2c) result in relatively brittle fracture. The amount of energy absarbed to fracture during shear impact is called herein shear impact resistance. The corresponding impact energy density as measured under the shear stressstrain curve is shown in Fig. 1c. The governing equation for shear is given by

$$
\text { IED }=\frac{1}{2}\left(\frac{\beta_{12 S^{\varepsilon} \varepsilon_{p S}}}{\beta_{v} \phi_{\mu 12}}\right)^{2} G_{.12}
$$


Note the similarity of Eqs. (7) and (6). Corresponding terms have analogous meanings, namely: $\beta_{12 S}$, correlation factor; $\varepsilon_{\mathrm{mpS}}$, in-situ matrix shear-fracture-strain; $\beta_{V}$, void contribution to the matrix shear strain; $\phi_{\mu 12}$, matrix shear-strain-magnification factor; $G_{212}$, composite shear modulus in the plane containing the fibers.

The important points noted in discussing Eq. (6) apply to corresponding terms in Eq. (7) as well. One additional point to be noted is that Eq. (7) describes also intralaminar shear delamination as will be described subsequently.

The graphical representation for typical fiber composites is shown in Fig. 6. In this figure the IED for shear is plotted as a function of the fiber volume ratio. The important points in Fig. 6 are: (1) Boron/ epoxy composites are superior in shear impact as compared with other fiber/epoxy composites when the fiber volume ratio is less than about 0.6. (2) The shear impact resistance of isotropic boron and S-glass fiber/epoxy composites is very sensitive to fiber volume ratio.

The variation of the shear IED as a function of matrix modulus for a graphite Modmor-I fiber/epoxy composite is shown in Table 5. As can be seen in this table, the shear IED increases very rapidly with increasing matrix modulus. The reason for this very rapid increase is the variation of the matrix shear-strain-magnification and the composite shear modulus (Table 5) with increasing matrix modulus. It should be noted that the shear IED increases more rapidly than the transverse IED as can be seen by comparing corresponding columns in Table 5. Longitudinal Impact Resistance from Fiber Pu11-Out Fiber composite fractured surfaces usually exhibit some debonding 
and fiber pul1-out. This fracture mechanism has been investigated extensively $[1-4]$

Two assumptions are made to derive the governing equation. These are: (1) the energy absorbed during impact is expanded in pulling-out the fibers and (2) the interface bond strength is approximated by the intralaminar shear strength. Assumption (2) was first introduced in Ref. 2. The detailed derivations leading to the governing equation are given in [6]. The result for the impact energy density from fiber pul1out is given by

$$
I E D=\frac{1}{8}\left(1-k_{v}\right)\left(\frac{\beta_{v} \phi_{\mu 12}}{\beta_{12 S^{\varepsilon} \varepsilon_{p S}}}\right) \frac{S_{f T}^{2}}{G_{z 12}}
$$

The symbols in Eq. (9) have been defined previously. Equation (8) describes IED due to fiber pull-out as a complex function depending on: fabrication process, fiber and void contents, constituent strength properties, and composite shear modulus. The variation of IED as a function of constituent elastic properties is not easily seen in Eq. (8) because the parameter $\left(\phi_{\mu 12} / G_{212}\right)$ depends on fiber and void contents, and on the constituent properties in a complex way. This parameter is defined herein as the "Debonding Parameter" because it is an indication of the local interface shear bond. Its dependence on matrix modulus and fiber volume ratio is shown in Fig. 7 for Modmor-I fiber/epoxy composites. Note the scales in this figure. The leaders from the curves point to the corresponding scales. For example the dependence of the $\left(\phi_{\mu 12} / G_{212}\right)$ on fiber volume ratio is represented by the upper curve with $\left(\phi_{\mu 12} / G_{i 12}\right)$ plotted on the right against $k_{f}$ on the top. 
The important points to be noted from Eq. (8) in conjunction with Fig. 7 are: (1) Local bonding is enhanced with increasing fiber volume ration (up to about 0.65 ) or increasing matrix modulus. (2) Impact energy density (IED) due to debonding can be increased by any or combinations of the following: poor interface bond, low in-situ matrix elongation-to-failure, large $\left(G_{f 12} / G_{\mathrm{m} 12}\right)$ ratio; and constituent selection which result in low shear modulus $\left(G_{212}\right)$ composition.

It is important to note that the parameters which enhance IED from debonding and fiber pull-out are quite detrimental to composite structural integrity with respect to strength and stiffness. Impact Resistance Due to Delamination

Delamination in the context used here refers to the delamination due to shear of interply layers in multilayered composites. The energy expanded is referred to herein as the "impact resistance due to delamination."

The governing equation to describe this resistance is based on the following assumptions: (1) Delamination occurs when the interlaminar shear strength has been exceeded. (2) Several interply layers could delaminate simultaneously. The detailed derivations are given in [6]. The resulting equation for the impact energy density from delamination is given by

$$
I E D=\frac{1}{2} N_{L D}\left(\frac{\beta_{12^{\varepsilon}}{ }_{m p S}}{\beta_{v} \phi_{\mu 12}}\right)^{2} G_{.12}
$$

where $\mathrm{N}_{L D}$ is the number of delaminated interply layers and all other symbols have been previously defined.

Note that Eq. (9) is identical with Eq. (7) except for the coeffi- 
cient $\mathrm{N}_{\mathrm{LD}}$. Therefore, the discussion following Eq. (7) and the important points noted there apply to Eq. (9) as well.

The additional point to be noted from Eq. (9) is, that for improved impact resistance, design the part to assure multi interply delamination. This should be applicable to high velocity impact as well as low. Longitudinal Impact with Cleavage and Fiber Pull-out

This type of impact resistance results in fractured surfaces consisting of broken fibers with debonding and fiber pul1-out. It was referred to as cleavage with debonding previously. The governing equation is a combination of Eqs. (3) and (8). The result for the impact energy density for this case is given by

$$
I E D=\left(I-k_{V}\right) \frac{S_{f T}^{2}}{2 E_{f}}\left[\beta_{f T}^{2} k_{f}+\frac{d_{f} k_{f D}}{4 L_{c}}\left(\frac{\beta_{v} \phi_{\mu 12}}{\beta_{12 S} \varepsilon_{m p S}}\right) \frac{E_{f}}{G_{Z 12}}\right]
$$

where $I_{c}$ is the length of the component subjected to uniform stress which cause fiber fracture. The other parameters in Eq. (10) have been previously defined.

It is important to note that the fiber pull-out contribution (second term in Eq. (10)) to impact resistance in Eq. (10) is strongly dependent on $\mathrm{L}_{\mathrm{c}}$. The following example will illustrate the point: Using typical values for Modmor-I fiber/matrix composite and assuming 40 percent fiber pul1-out, the contribution is approximately $0.3 / \mathrm{L}_{\mathrm{c}}{ }$ This contribution is negligible for longitudinal impact where $I_{c}$ is quite large. However, the fiber pull-out contribution will be significant in the case of localized or bending impact.

The fiber pull-out contribution will, in general, be negligible (less than about 1 to 2 percent) if 
$\left(\frac{d_{f}}{L_{c}}\right)\left(\frac{E_{f}}{G_{l 12}}\right)<10^{-5}$

Equation (10) indicates that composites with high modulus and low intralaminar shear strength are good candidates for high impact resistance. Since Eq. (10) is a combination of Eqs. (3) and (8) the discussion following these equations applies to $\mathrm{Eq} .(10)$ as well. HYBRID COMPOSITES TAILOR-MADE FOR IMPROVED IMPACT RESISTANCE

Hybrid composite is the term used for a composite which consists of two or more different fiber matrix combinations. Typical examples are: Modmor-I/epoxy-G1ass/epoxy-Modmor-I/epoxy; HTS/epoxy-Thorne1-50/ epoxy-HTS/epoxy and others.

Using these composites for improved impact resistance is a major contribution of this investigation. The concept was discovered during the experimental portion of the investigation. It was observed that some of the impacted cantilever specimens exhibited combined fracture modes consisting of fiber breakage, fiber pull-out and interply delamination.

The hybrid composite takes advantage of two or more of these modes to improve impact resistance: It is an important and useful concept in designing structural components in general. The impact resistance of hybrid composites is thus not a material characteristic.

The concept is illustrated here, by applying it to the cantilever structure shown in Fig. 8. The governing equation for impact energy density is given by 


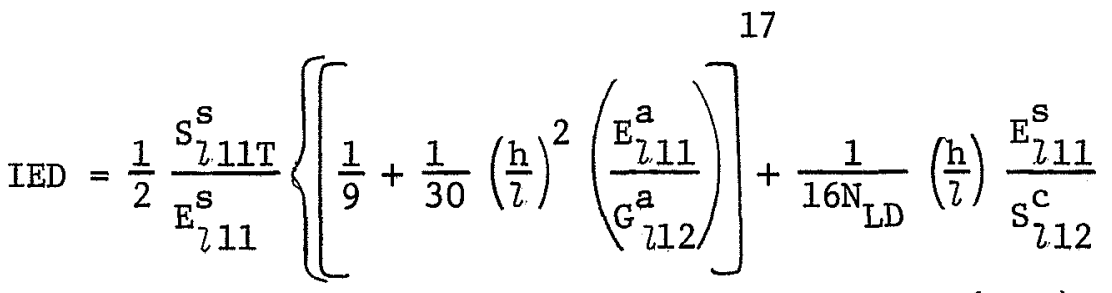

$$
\begin{aligned}
& \left.+\frac{\pi}{16}\left(\frac{N_{f D} d_{f}^{3}}{b h l}\right)\left(\frac{E_{l 11}^{s}}{s_{l, 12}^{s}}\right)\left(\frac{s_{f T}^{s}}{s_{l .11 T}^{s}}\right)^{2}\right\}
\end{aligned}
$$

The undefined notation in Eq. (12) is as follows: the superscripts (a), (s), and (c) represent averaged core-shell, she11 and core, respectively. The subscript (1) refers to unidirectional composite properties along the direction indicated by the numerical subscripts following ( $\downarrow$ ). The variables $b, h$, and $l$ represent width, depth, and length of the cantilever, respectively. See also Fig. 8. The variables $d_{f}, N_{f D}$, and $N_{\text {LD }}$ represent fiber diameter, number of fibers that pulled out, and number of layers that delmainated, respectively.

Examining Eq. (12) reveals that the shear contribution depends on $E_{l 11}^{\mathrm{a}} / \mathrm{G}_{2.12}^{\mathrm{a}}$ and both fiber pul1-out and delamination depend on the parameter $E_{211} / G_{212}$. This means that in order to take advantage of the high shear contribution of, fiber pul1-out and/or delamination, high longitudinal modulus, low shear modulus and low intralaminar strength composites should be selected. Some composites which meet this criterion are Thorne1-50, Modmor-I, and HMOF fibers in a resin matrix-

There are three other sets of parameters in Eq. (12) which need careful examination in designing hybrid composites for improved impact resistance. These are: (1) $(h / l)^{2}$ - for the shear contribution; (2) $\left(\mathrm{h} / \mathrm{N}_{\mathrm{LD}} \eta\right)$ - for delamination; and (3) $\left(\mathrm{d}_{\mathrm{f}^{\mathrm{N}}}^{3} \mathrm{fD} / \mathrm{bh} l\right)$ - for fiber pul1out.

The shear contribution will be greater than 3 percent when 


$$
(l / h)^{2}>10 \mathrm{E}_{\imath .11}^{\mathrm{a}} / \mathrm{G}^{\mathrm{a}} \mathrm{l12}
$$

The contribution of the fiber pull-out will be greater than 3 percent when

$$
\left(\frac{d_{f}^{3} N_{f D}}{b h l}\right)>0.02\left(\frac{s_{l 12 S}^{s}}{E^{s}}\right)
$$

The contribution of the delamination will be greater than 3 percent when

$$
\left(\frac{h}{N_{L D} i}\right)>0.06\left(\frac{S_{l 12 S}^{c}}{E_{l 11}^{S}}\right)
$$

The inequality

$$
\mathrm{s}_{212 \mathrm{~S}}^{\mathrm{c}} \leq \frac{1}{4}\left(\frac{\mathrm{h}}{2}\right) \operatorname{MIN}\left(\mathrm{s}_{211 \mathrm{~T}}^{\mathrm{s}}, \mathrm{s}_{\eta 11 \mathrm{C}}^{\mathrm{s}}\right)
$$

must be satisfied for delamination. The variable $\mathrm{s}_{\text {IIIC }}^{\mathrm{s}}$ denotes longitudinal compressive strength.

Equation (12) in conjunction with the inequalities Eqs. (13-16) and provide relations which can be used to select parameters in designing composites with improved impact resistance. They were used in this investigation to guide the selection of the hybrid composites.

The inequalities Eqs. (13-16) can be expressed in terms of constituent properties by using the micromechanics relations for $S_{211 T}$, $\mathrm{S}_{211 \mathrm{C}}, \mathrm{S}_{212 \mathrm{~S}}$, and $\mathrm{E}_{211^{\circ}}$

EXPERIMENTAL INVESTIGATION

This portion of the investigation consisted of carrying out miniature-Izod [17] impact tests to verify qualitatively the theoretical considerations and concepts described in the "Theoretical Investigation" Section. 
Materials and Specimen Fabrication

Graphite, glass and HMOF fibers in an epoxy resin matrix were used in the experimental investigation. The various fibers are listed in Table 6. All fiber material was drum wound and impregnated with the epoxy resin ERL 2256-ZZL0820 (27.0 pph resin).

Composites were fabricated by means of a unidirectional lay-up of a number of "B" staged plies to yield the thickness desired. Most of the composites consisted of fibers of one particular type. Some hybrid composites were also fabricated that consisted of two fiber types in the lay-up with selected thickness and position of each. The composites were cured under heat and pressure in a matched-die mold. Complete curing conditions are included in Table 6.

Miniature Izod specimens were machined from the fabricated composites in both the longitudinal and transverse directions. The finished specimen dimensions were $7.9 \times 7.9 \times 37.6 \mathrm{~mm}$.

Test Apparatus and Procedure

The impact machine used was a modified Be1l. Telephone Laboratory pendulum type (Fig. 9). The design capacity of the pendulum was 240 centimeter-Newtons (27 inch-pounds). Addition of weights to the pendulum increased the capacity to 1010 centimeter-Newtons (114 inchpounds). The striking velocity of the pendulum was $345 \mathrm{~cm}$ per second. The Izod specimens were struck at their free end, $22 \mathrm{~mm}$ from the edge of the grip. The specimen length in the grip was $14 \mathrm{~mm}$. A "dead weight" load was applied to the grip to assure uniform gripping of specimens. Composites of one particular fiber were tested in both the longitudinal and transverse directions. Hybrid composites were generally 
tested in the longitudinal direction with the plies parallel to the striking pendulum. The angular displacement of the pendulum after impact was an inverse measure of the impact energy. Typical fractured specimens from this method of testing are shown in Fig. 10. EXPERIMENTAL RESULTS AND DISCUSSION

Longitudinal and Transverse Impact

Several specimens of each composite system were tested in longitudinal and transverse impact. Also specimens from the matrix system were tested. The results are presented in Bar-Graph form in Fig. 11. The adjacent bars have the following meaning: the left bar denotes longitudinal while the right denotes transverse impact. The scatter is indicated by the light lines within the bar.

Photomicrographs of typical fracture surfaces are shown in Fig. 12. Note the fracture modes, cleavage, and cleavage with fiber pul1-out. Photographs of fractured specimens are shown in Fig. 10. Impact resistance versus short-beam intralaminar shear strengths for several of these composites are given in Fig. 13. The intralaminar shear strengths are needed to assist with the theoretical impact resistance ranking of the test specimens.

Measured results of longitudinal impact normal and paralle1 to the lamination directions were identical. This is to be expected in unidirectional composites with nonmetallic matrices. Discussion of Experimental Results and Comparison of Ranking

Examination of Figs. 10 and 11 reveal that: (1) Those composites which exhibit more than one fracture mode have higher impact resistance in genera1. (2) Composite transverse impact results in brittle fracture 
and the value is considerably lower than that of the matrix. Some fiber splitting occurs in the Thornel fiber composites. (3) The hybrid composite experienced two or more fracture modes.

Averaged values of the experimental results are summarized in Table 6. The last two columns of this table contain the ranking with respect to impact resistance. The numbers enclosed in circles in these columns represent the ranking of the measured values. The numbers enclosed in squares represent the predicted ranking. As can be seen, the ranking is identical. The predicted ranking was obtained as follows: For the longitudinal ranking, Eq. (13) was used in conjunction with Table 1 and Fig. 13. For the transverse ranking Eq. (6) was used in conjunction with Fig. 13. The use of Fig. 13 for the transverse strength is acceptable because both intralaminar shear and transverse composite strengths exhibit similar trends.

It is interesting to note in Table 6 that one of the hybrid composites (HTS/T505/HTS) had larger impact resistance than either of the two constituent composites. The explanation is that the hybrid composite had more delaminated surfaces. This, of course, is the essence of the hybrid composite concept for improved impact resistance.

The important point to keep in mind from this discussion is that theoretical expressions can be constructed to predict impact resistance at least on a qualitative basis. These expressions can be used to guide research for constituent materials and design concepts for improved impact resistance.

CONCLUSIONS

Results from this investigation of gross-type-impacts of composites 
involving relatively long impact contact times lead to the following conclusions:

1. The impact resistance of unidirectional composites is ranked using elementary composite mechanics and criteria are presented to guide design for improved resistance.

2. Theoretical results show that in composites with high fiber-tomatrix modulus ratios, the longitudinal impact resistance is fiber controlled. When this ratio is twenty, the matrix contribution is less than 5 percent. However, the transverse and shear impact resistances are matrix controlled.

3. Theoretical results show that in composites with fiber-to-matrix modulus or strength ratios about four, the longitudinal impact resistance could be matrix controlled. In this case, the presence of microresidual stresses decreases the impact resistance considerably.

4. Theoretical considerations indicate that the impact resistance can be improved by designing the composite so that fiber breaks, fiber debonding with fiber pull-out and partial delamination take place at the same time. Any combinations of these fracture modes will also improve the impact resistance.

5. Theoretical considerations also show that the impact resistance is sensitive to void and fiber contents and to certain fabrication factors which are reflected in the in-situ constituent properties.

6. The experimental results indicate three prevalent longitudinal failure modes due to impact. These are cleavage, cleavage with some fiber pul1-out, and cleavage combined with partial delamination due to intralaminar shear failure. 
7. The transverse failure mode was cleavage. The fracture surface included matrix fracture, fiber debonding, and some fiber splitting. The experimental results showed that the impact resistance was the same whether the specimen was impacted parallel or normal to the lamination direction.

8. Ranking of predicted results was in good agreement with that of measured results from notched Charpy Impact, cryogenic fracture toughness, stress intensity, and unnotched Izod impact.

9. The hybrid composite concept is an efficient composite design to combine high strength and high stiffness with high impact resistance. REFERENCES

[1] Tetelman, A. S., "Fracture Processes in Fiber Composite Materials," Adhesion, ASTM STP 460, Composite Materials: Testing and Design, ASTM STP 460, Am. Soc. Testing Mats., 1969, p.540, p. 473.

[2] Novak, R. E., "Fracture in Graphite Filament Reinforced Epoxy Loaded in Shear," Composite Materials: Testing and Design, ASTM STP 460, Am. Soc. Testing Mats., 1969, p. 540.

[3] Kelly, A., "Interface Effects and the Work of: Fracture of a Fibrous Composite," NPL-IMS-10, National Physical Lab., Feb. 1970.

[4] Outwater, J. O. and Murphy, M. C., "Fracture Energy of Unidirectional Laminates," Modern Plastics, Vol. 47, Sept. 1970, p. 160.

[5] Rotem, A. and Lifshitz, J. M., "Longitudinal Strength of Unidirectional Fibrous Composite Under High Rate of Loading," 26th Annual SPI Conference, 197I, Sec. 10-G.

[6] Chamis, C. C., Hanson, M. P. and Serafini, T. T., "Designing for Impact Resistance with Unidirectional Fiber Composites," Proposed NASA Technical Note, Nat. Aeronautics and Space Administration. 
[7] Chiao, T. T. and Moore, R. L., "Stress-Rupture of S-Glass/Epoxy Multifilament Strands," Journal of Composite Materials, Vol. 5, 1971, p. 2.

[8] Chamis, C. C., "Thermoelastic Properties of Unidirectional Filamentary Composites by a Semiempirical Micromechanics Theory," Science of Advanced Materials and Process Engineering, Vol. 14, Western Periodicals Company, 1968, Paper I-4-5.

[9] Chamis, C. C., "Failure Criteria for Filamentary Composites," NASA TN D-5367, Nat. Aeronautics and Space Administration, 1969.

[10] Daniel, I. M., "Photoelastic Study of Crack Propagation in Composite Models," Journal of Composite Materials, Vol. 4, 1970, p. 178.

[II] Broutman, L. J. and Sahu, S., "The Effect of Interfacial Bonding on the Toughness of Glass Filled Polymers," 26th Annual SPI Conference, 1971, Sect. 14-C.

[12] McGarry, F. J. and Mandell, J. F., "Fracture Toughness of Fiber Reinforced Composites," Research Report R70-79, Massachusetts Inst. Tech., Dec. 1970 .

[13] Aulenbach, T. H, et al., "Fracture Toughness Testing of Fibrous Glass Resin Composites," presented at the 25th SPI Annual Conference, Washington, D.C., Feb. 6-9, 1970.

[14] Bacon, J. F., "Investigation of the Kinetics of Crystallization of Several High Temperature Glass Systems," Rep. J910939-3, United Aircraft Research Lab., Sept. 1970.

[15] Cooper, R. E., "The Work-To-Fracture of Brittle-Fibre Ductile-Matrix Composites," Journal of the Mechanics and Physics of Solids, Vol. 8, 1970, p. 179. 
[16] Patsis, A. V., et al., "Correlation of Graphite-Fiber/Epoxy Composite Strength rith Matrix Tensile Properties," Proposed NASA. Technical Note, Nat. Aeronautics and Space Administration.

[17] Compton, W. A., and Steward, K. P., "Test Specifications Manual Composite Materials For Turbine Compressors," AFML-TR-68-31, Pt. II, Solar Div., International Harvester, Apr. 1968.

[18] Alfring, R. and Simon, R. A., "Properties of Graphite Fiber Composites at Cryogenic Temperatures," NOLTR-69-183, NASA-CR-72652, Naval Ordnance Lab., May 1970.

[19] Chamis, C. C., "Computer Code for the Analysis of Multilayered Fiber Composites - Users Manual," NASA TN D-7013, Nat. Aeronautics and Space Administration, 1971. 


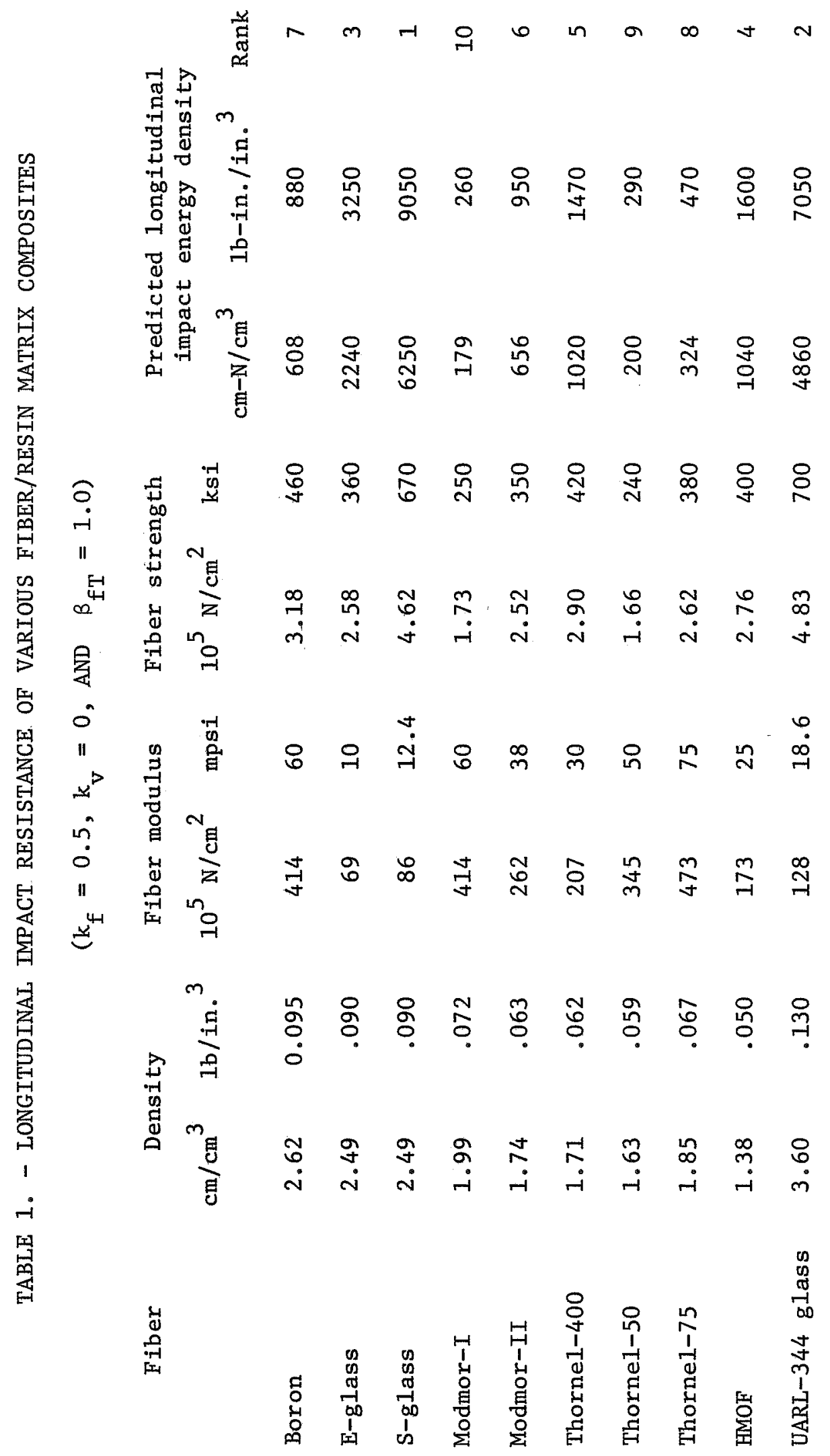




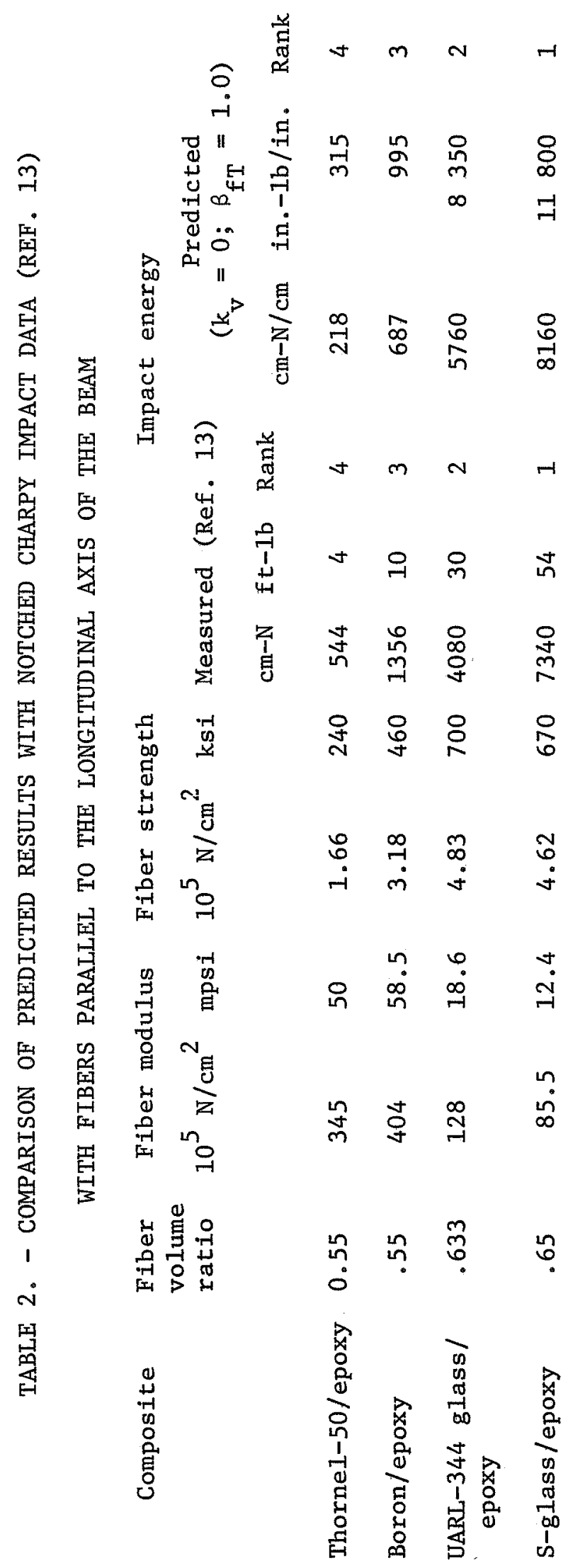




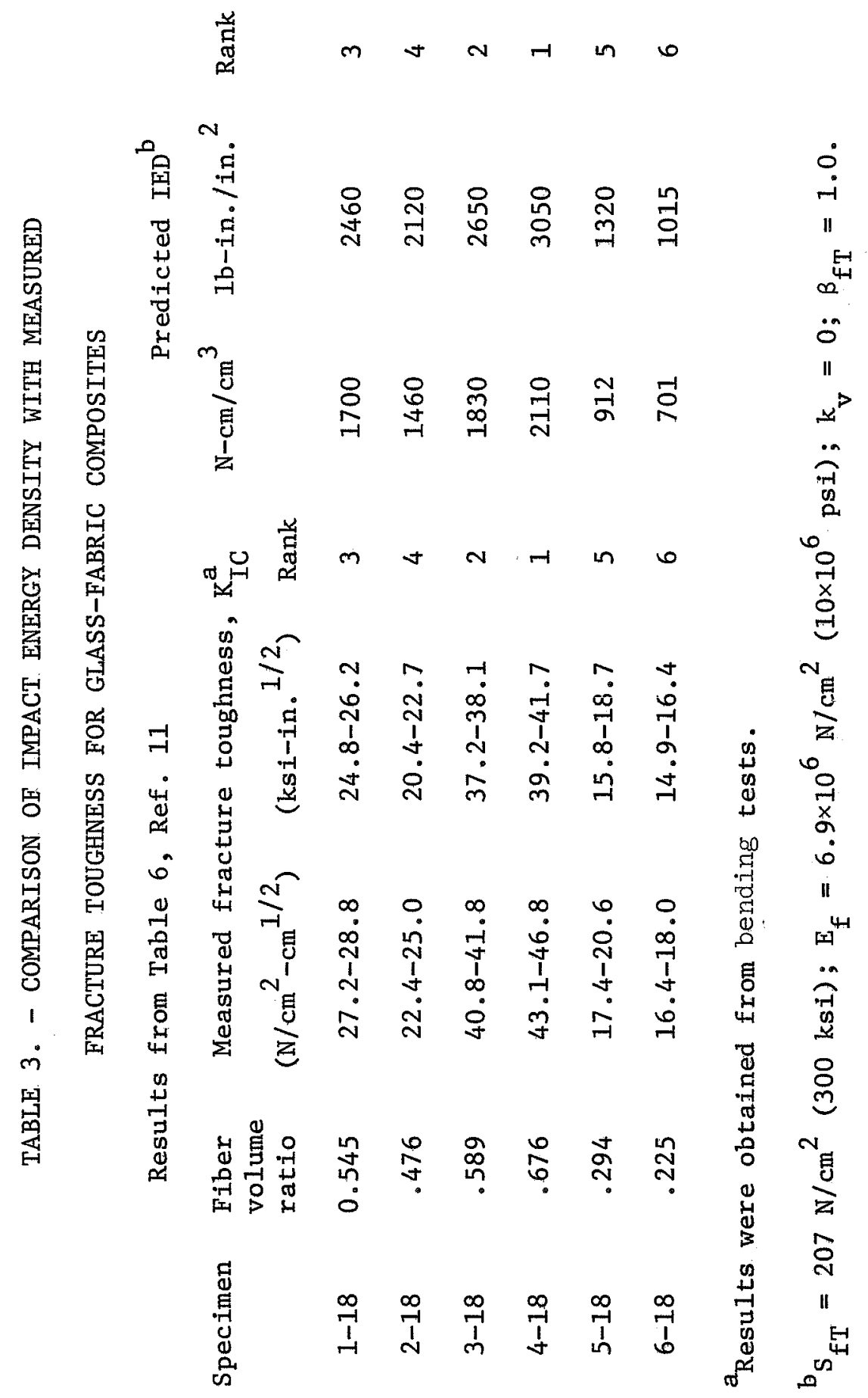




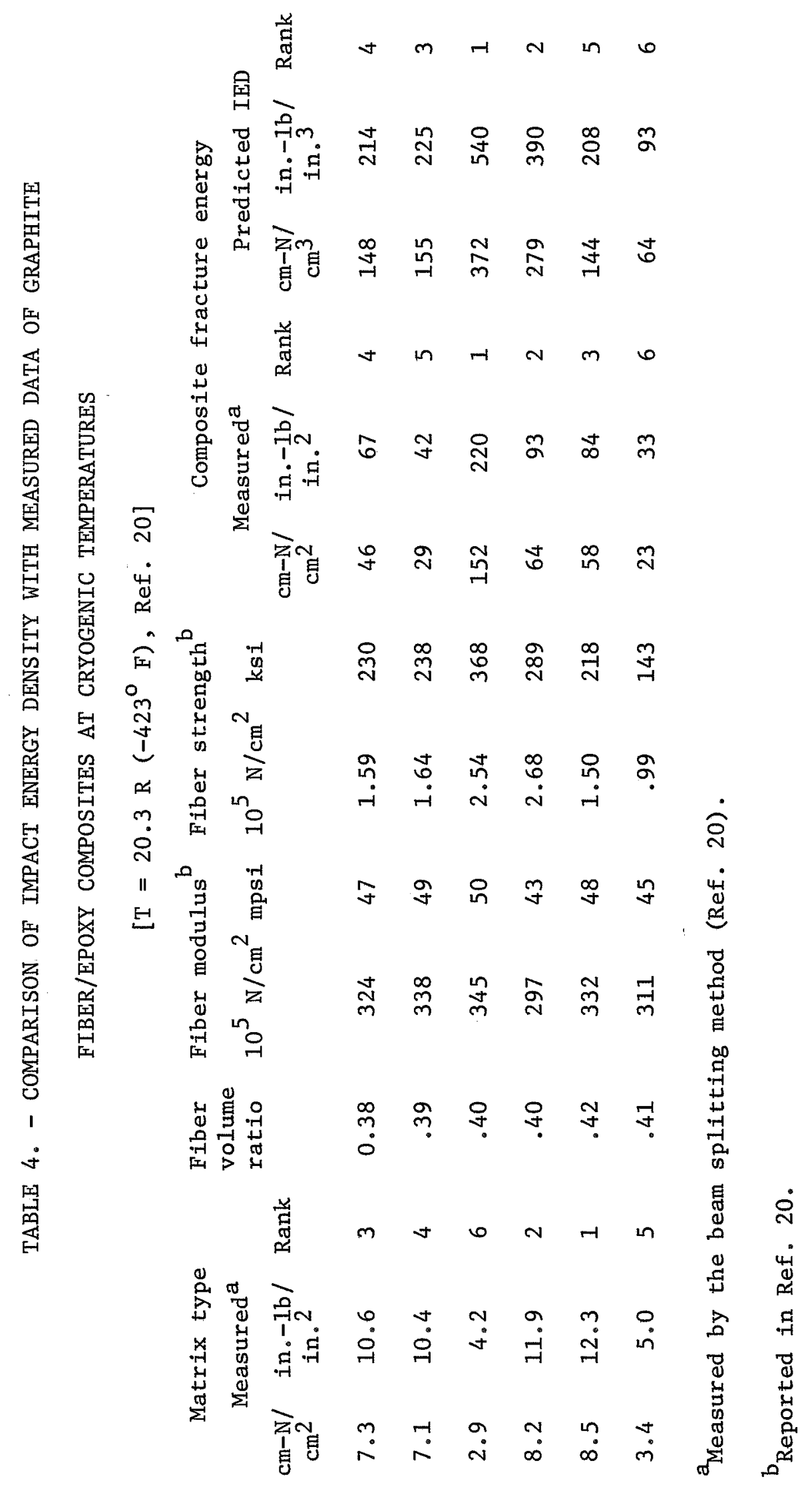




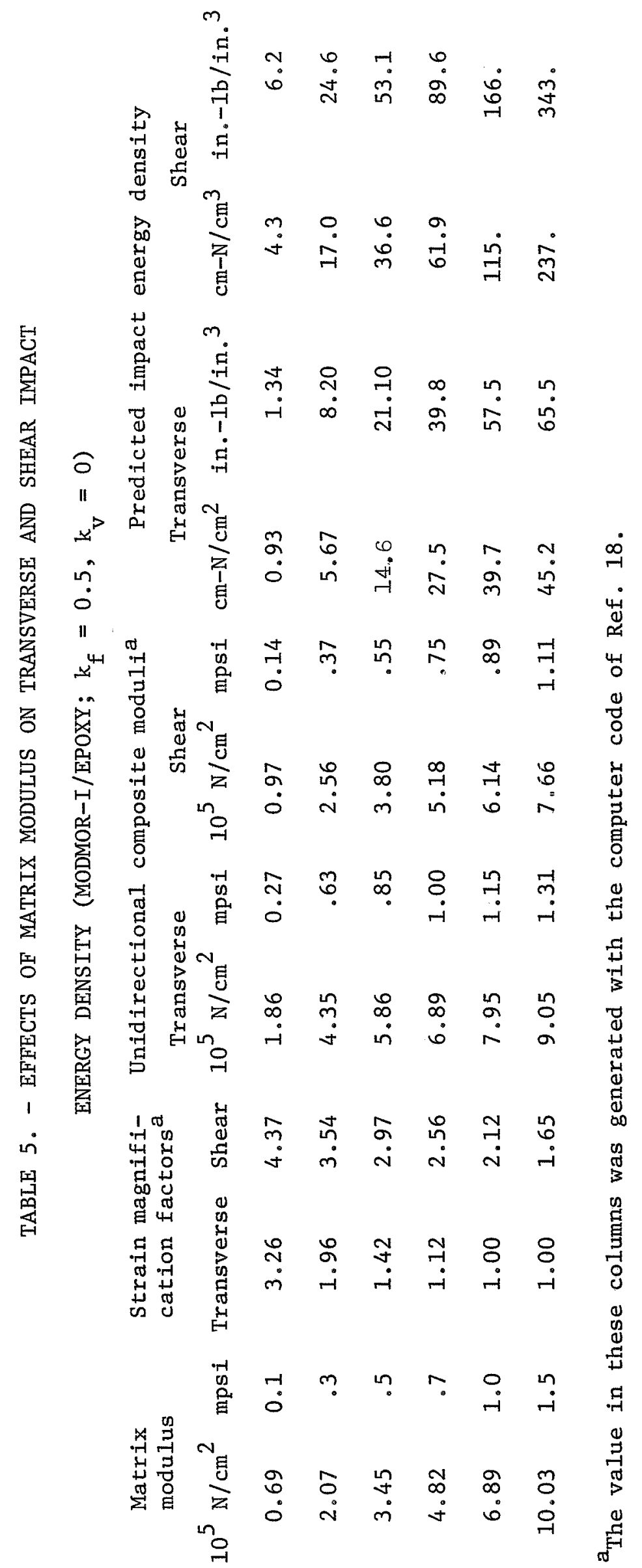


TABLE 6. - MINIATURIZED IZOD IMPACT DATA FOR FIBER-EPOXY ${ }^{(a)}$ COMPOSITES

\begin{tabular}{|c|c|c|c|c|c|c|c|c|}
\hline \multirow[t]{3}{*}{ Fiber } & \multirow[t]{3}{*}{ Type } & \multirow[t]{3}{*}{$\begin{array}{l}\text { Surface } \\
\text { treatment }\end{array}$} & \multirow{3}{*}{$\begin{array}{l}\text { Fiber } \\
\text { volume } \\
\text { ratio }\end{array}$} & \multirow[t]{3}{*}{$\begin{array}{l}\text { Fiber } \\
\text { direction }\end{array}$} & \multicolumn{2}{|c|}{$\begin{array}{c}\text { Average impact } \\
\text { energy }\end{array}$} & \multicolumn{2}{|c|}{ Ranking $^{\mathrm{e}}$} \\
\hline & & & & & & & Long. & Trans. \\
\hline & & & & & $\mathrm{cm}-\mathrm{N}$ & in. $-1 b$ & & \\
\hline \multirow[t]{2}{*}{ Graphite } & T505 & (b) & 0.532 & Long. & 85.9 & 7.6 & (5) 5 & (3) 3 \\
\hline & & & & Trans. & 7.9 & 0.7 & & \\
\hline \multirow[t]{2}{*}{ Graphite } & T50 & Polyviny1 & 0.583 & Long. & 208.0 & 18.4 & (4) 4 & (5) 5 \\
\hline & & & & Trans. & 3.4 & 0.3 & & \\
\hline \multirow[t]{2}{*}{ Graphite } & HTS & (c) & 0.523 & Long. & 56.5 & 5.0 & (6) 6 & (2) 2 \\
\hline & & & & Trans. & 14.7 & 1.3 & & \\
\hline \multirow[t]{2}{*}{ Graphite } & MI & None & 0.542 & Long. & 215.0 & 19.0 & (3) 3 & (4) 4 \\
\hline & & & & Trans. & 4.5 & 0.4 & & \\
\hline \multirow[t]{2}{*}{ Glass } & $\mathrm{S}$ & (d) & 0.486 & Long. & 757.0 & 67.0 & (1) 1 & (1) 1 \\
\hline & & & & Trans. & 15.8 & 1.4 & & \\
\hline \multirow[t]{2}{*}{ HMOF } & & --- & -- & Long. & 280.0 & 24.8 & (2) 2 & (5) \\
\hline & & & & Trans. & 3.4 & 0.3 & & \\
\hline
\end{tabular}

$\begin{array}{llccccc}\text { Graphite } & \text { HTS } & 0.598 & \text { Long. } & 116.3 & 10.3 & 3 \\ \text { T505 } & & \text { Trans. } & 11.3 & 1.0\end{array}$

$\begin{array}{llllll}\text { Graphite HMS } & 0.536 & \text { Long } & 132.0 & 11.7 & 2\end{array}$

MI

Graphite HMS $\quad$-- $\quad$ Long. $\quad 232.0 \quad 20.5 \quad 1$

appoxy resin - ERL 2256/AAL 0820, Union Carbide Corp. "B" stage of impregnated fiber $-93^{\circ} \mathrm{C}, 45 \mathrm{~min}$. Mylar cover, cure cycle - under 50 psi pressure, 2 hrs $-82^{\circ} \mathrm{C}, 3 \mathrm{hrs}-148^{\circ} \mathrm{C}$.

${ }^{b}$ Epoxy compatible - Union Carbide Corp.

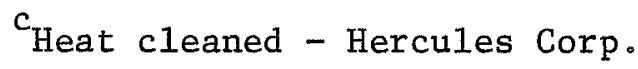

$d_{901}$ - Owens Corning Fiberglas Co.

e Measured rank, Predicted rank. 

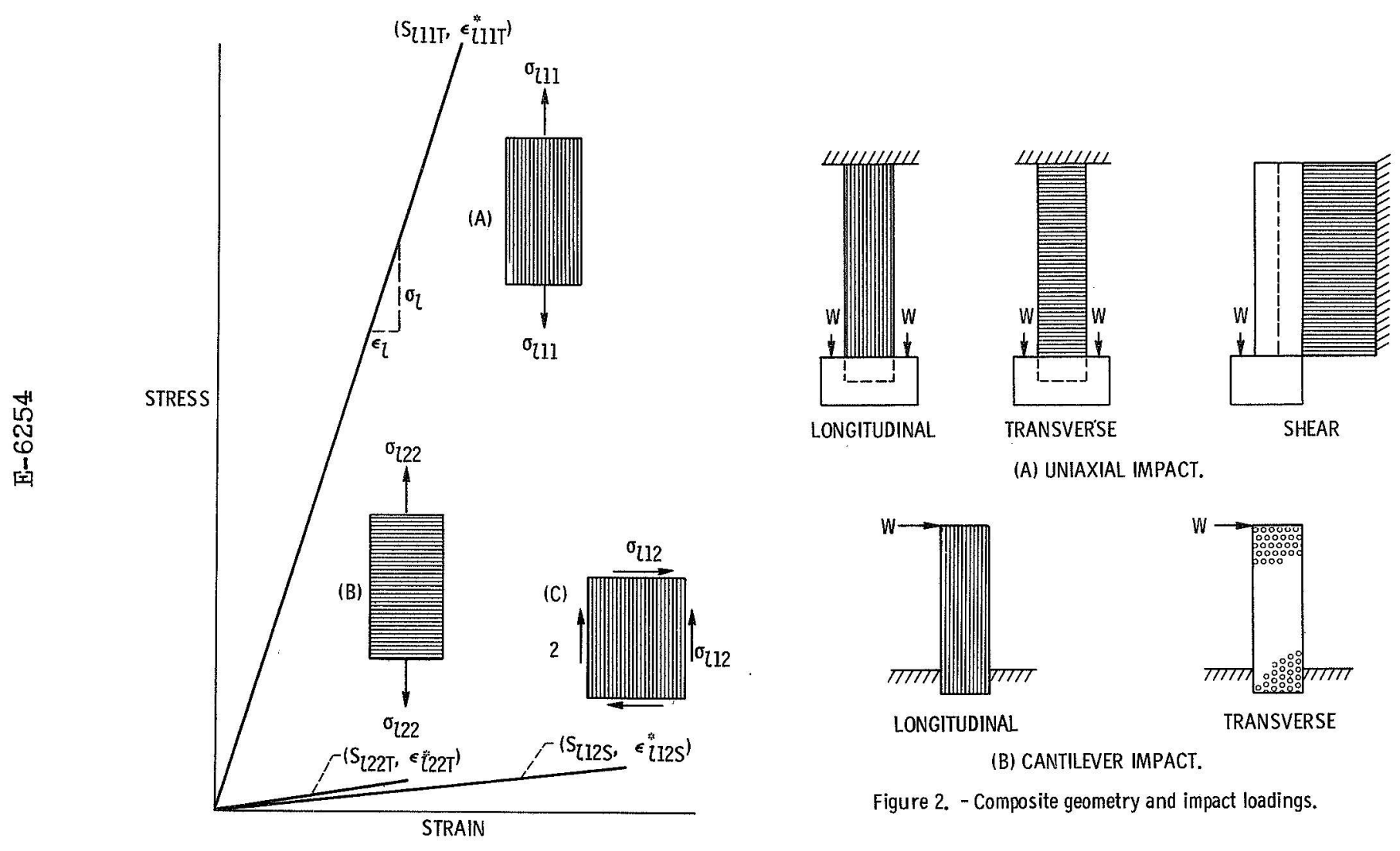

(A) UNIAXIAL IMPACT.
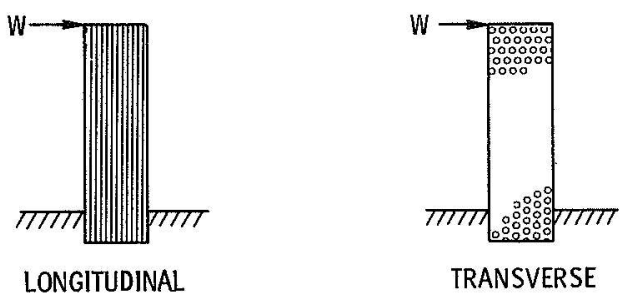

(B) CANTILEVER IMPACT.

Figure 2. - Composite geometry and impact loadings.

Figure 1. - Typical stress-strain curves of unidirectional fiber composite material subjected to high rate of loading.

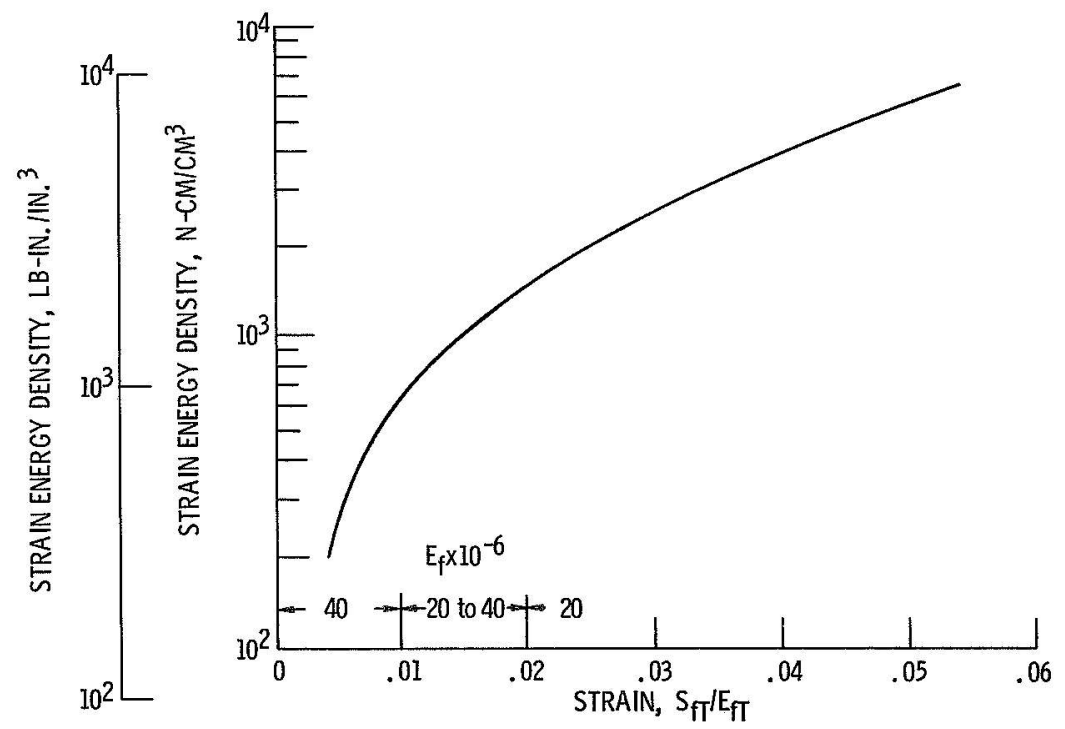

Figure 3. - Potential impact resistance of fiber composite materials from table I. 


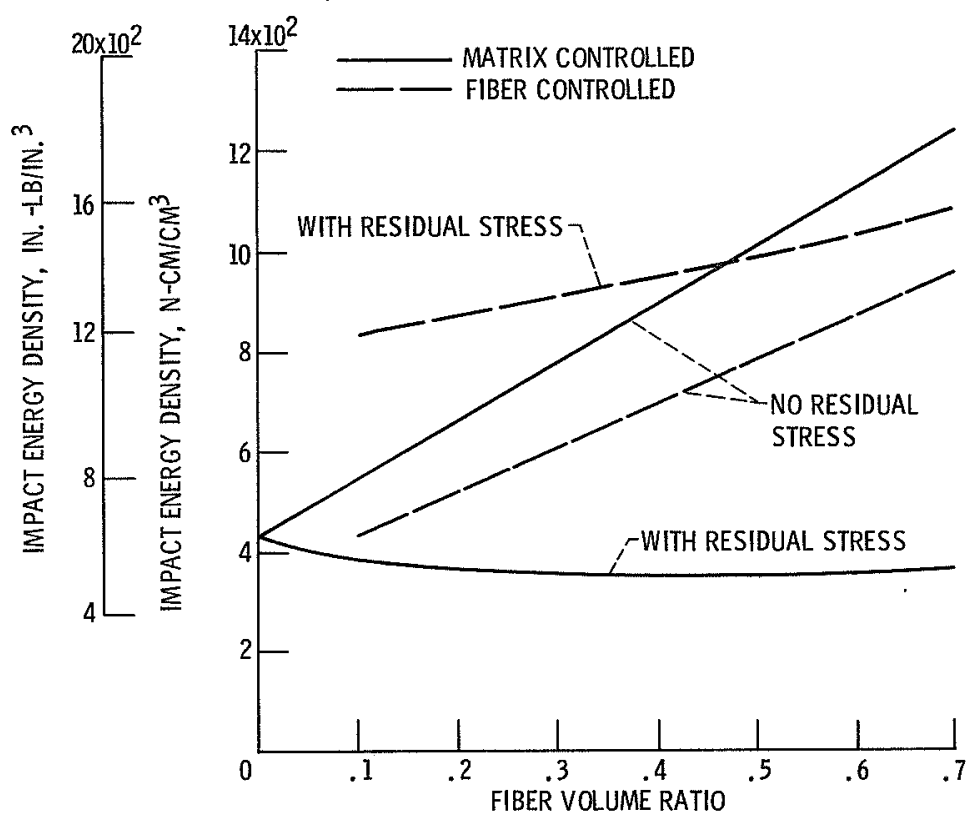

Figure 4. - Theoretical longitudinal impact resistance of (boron-silicon carbide/ titanium unidirectional composite) processing temperature, $1500^{\circ} \mathrm{F}$.

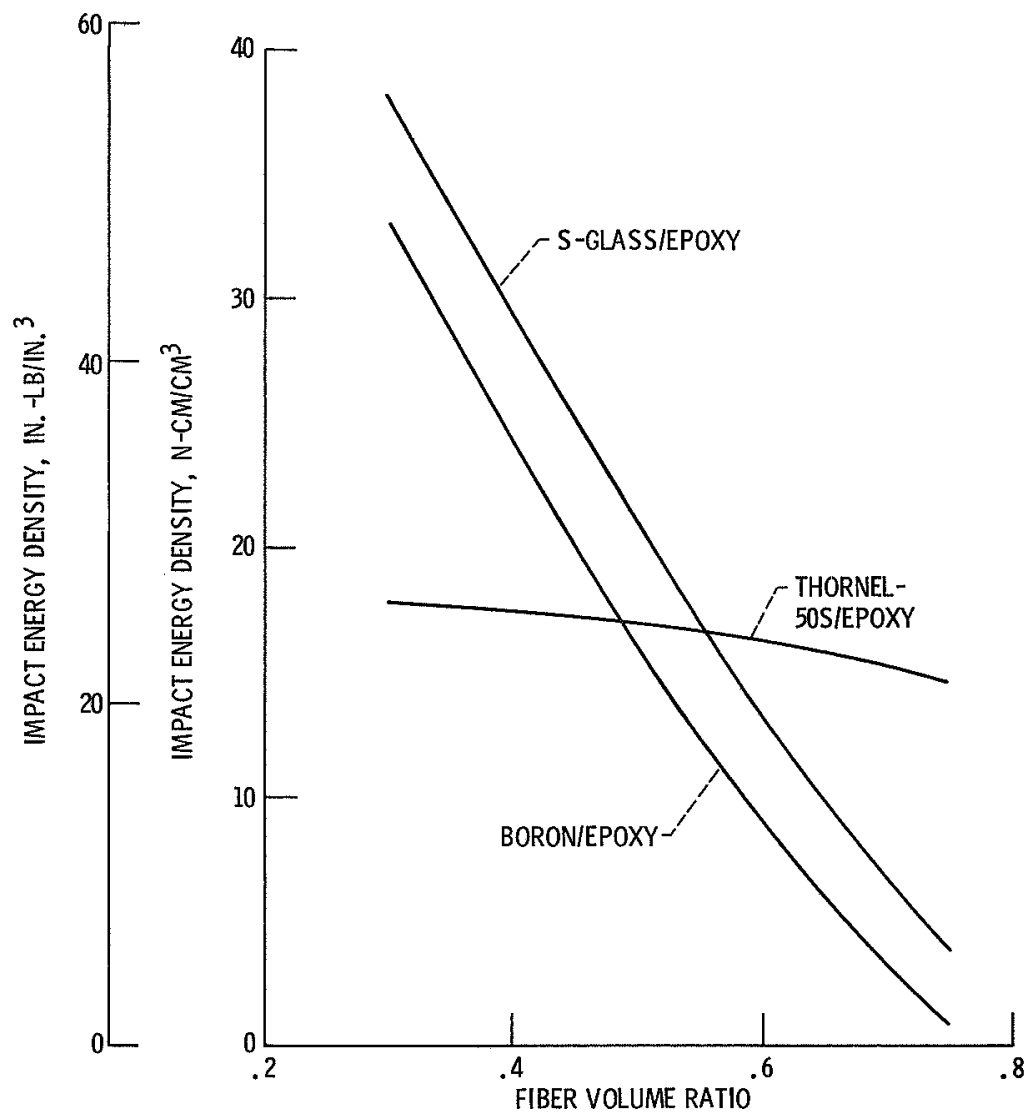

Figure 5. - Theoretical transverse impact resistance of unidirectional composites. 


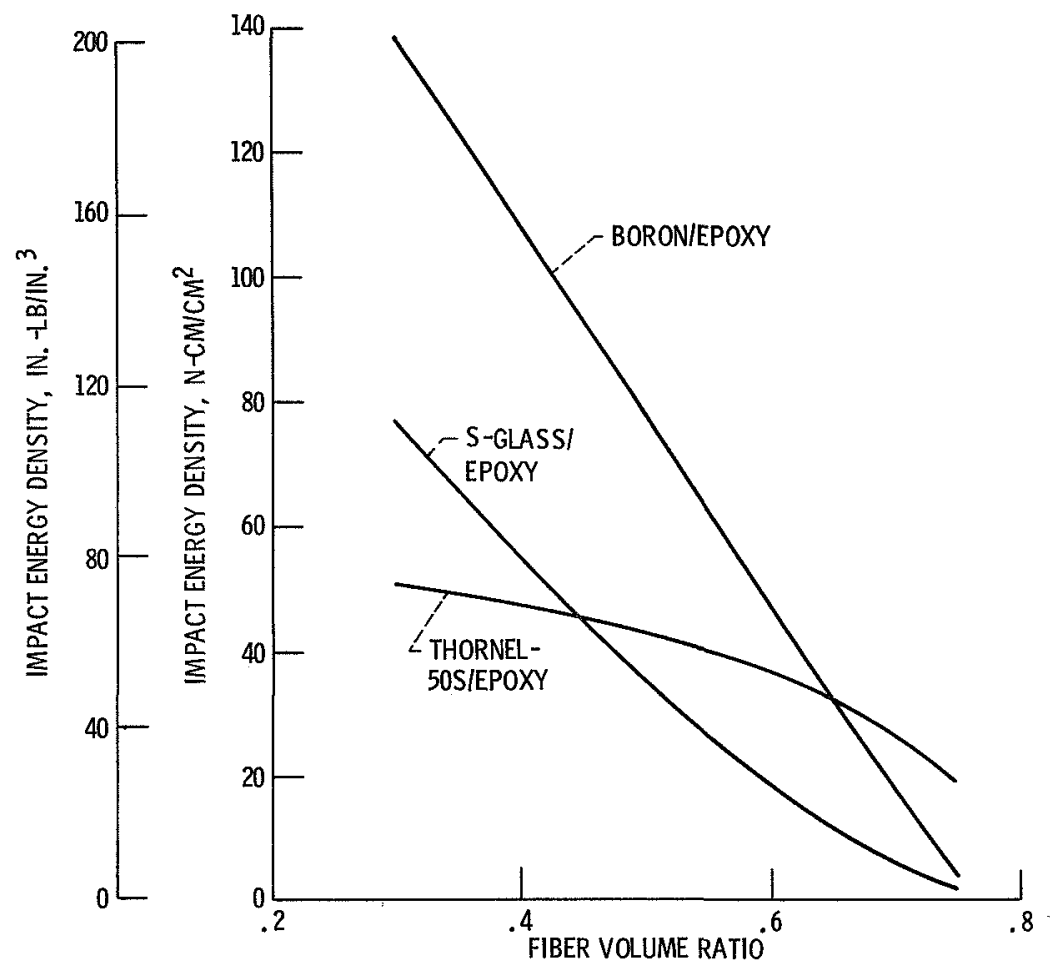

Figure 6. - Theoretical shear impact resistance of unidirectional composites.

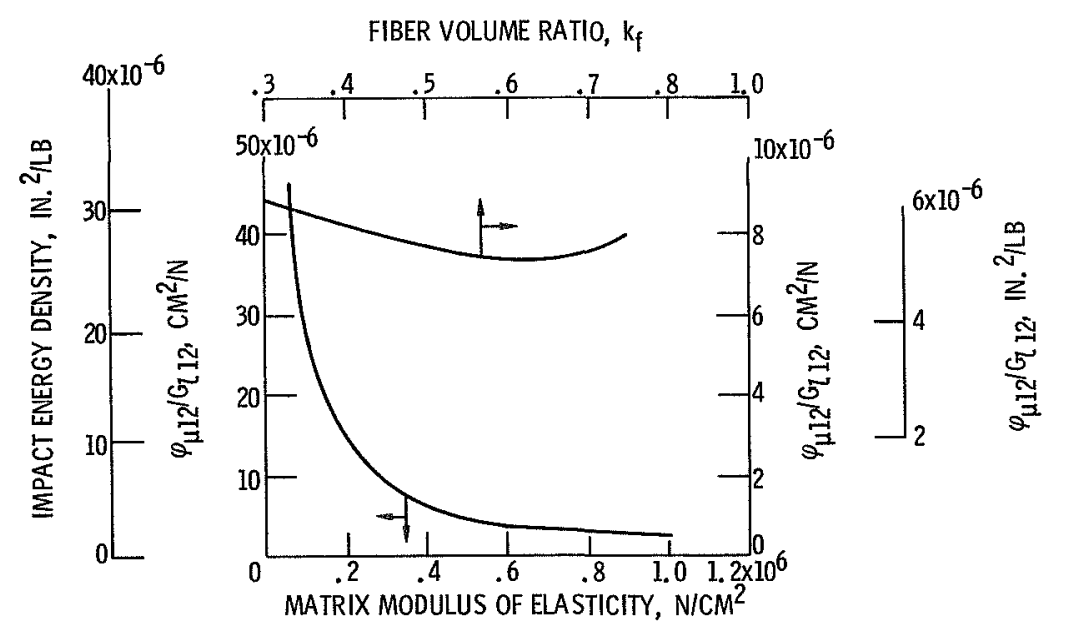

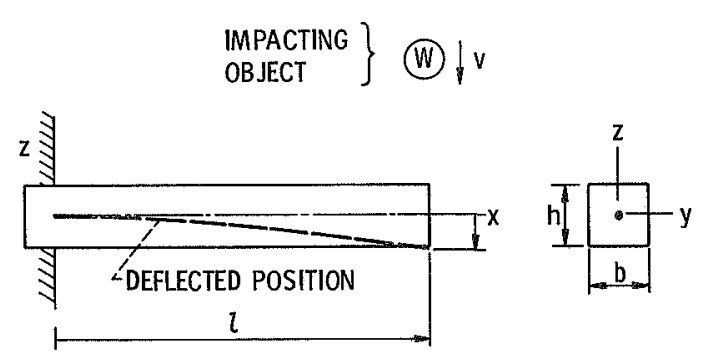

Figure 8. - Cantilever subjected to impact.

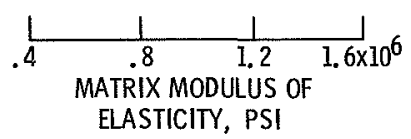

Figure 7. - Debonding parameter for Modmor-I/epoxy composite with zero voids. 

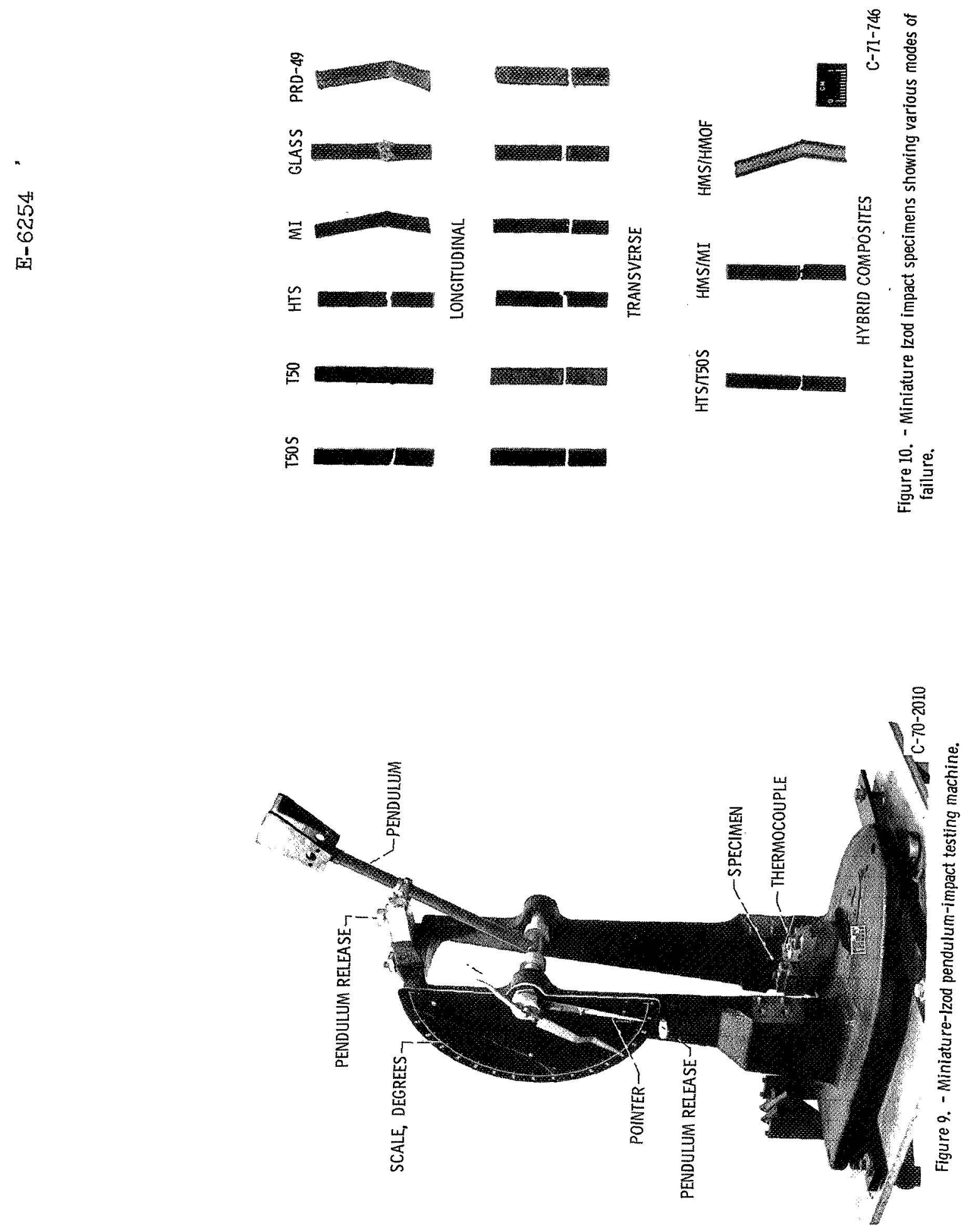


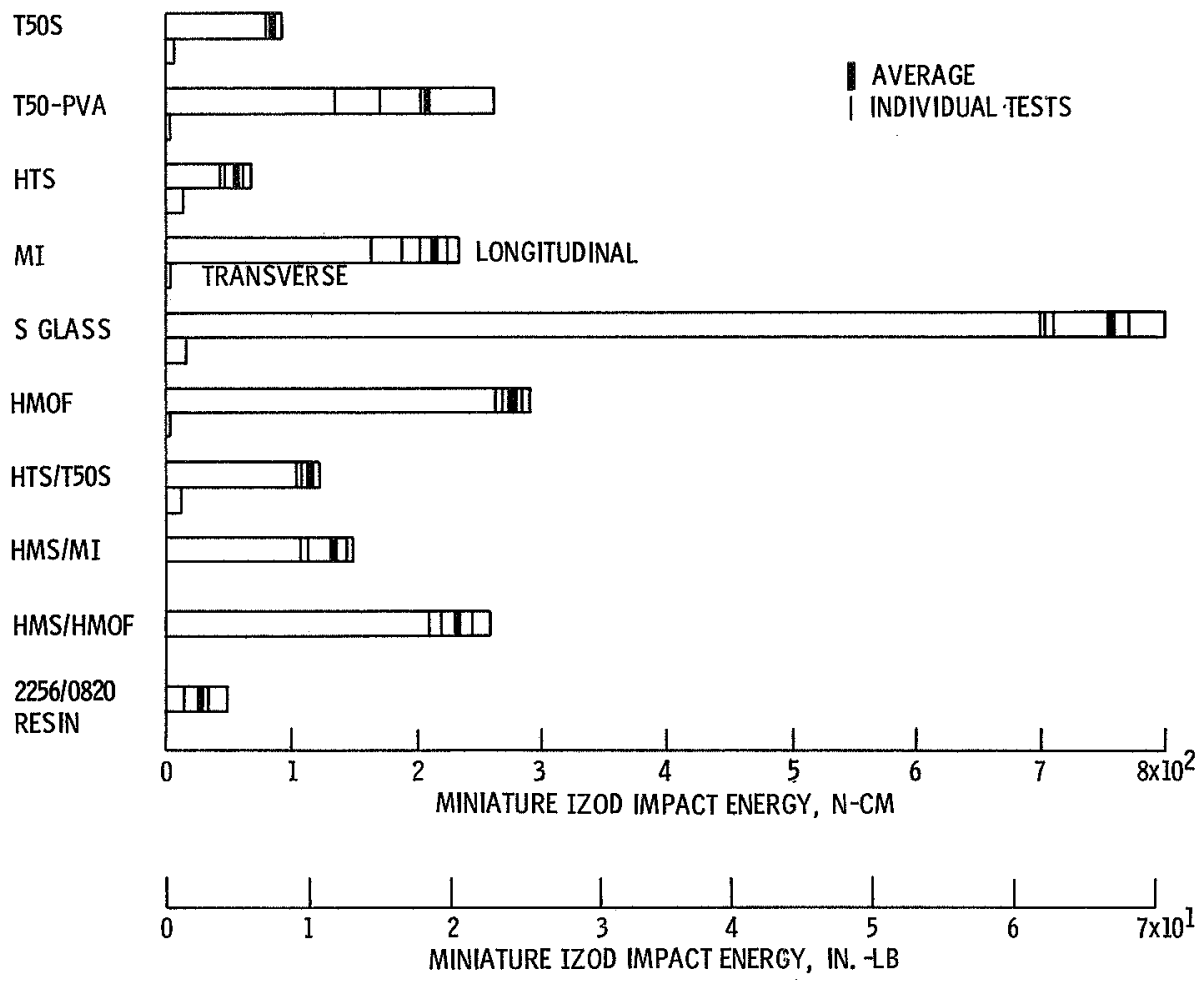

Figure 11. - Miniature IZOD impact energy of fiber/ERL 2256-2210820 composite. 

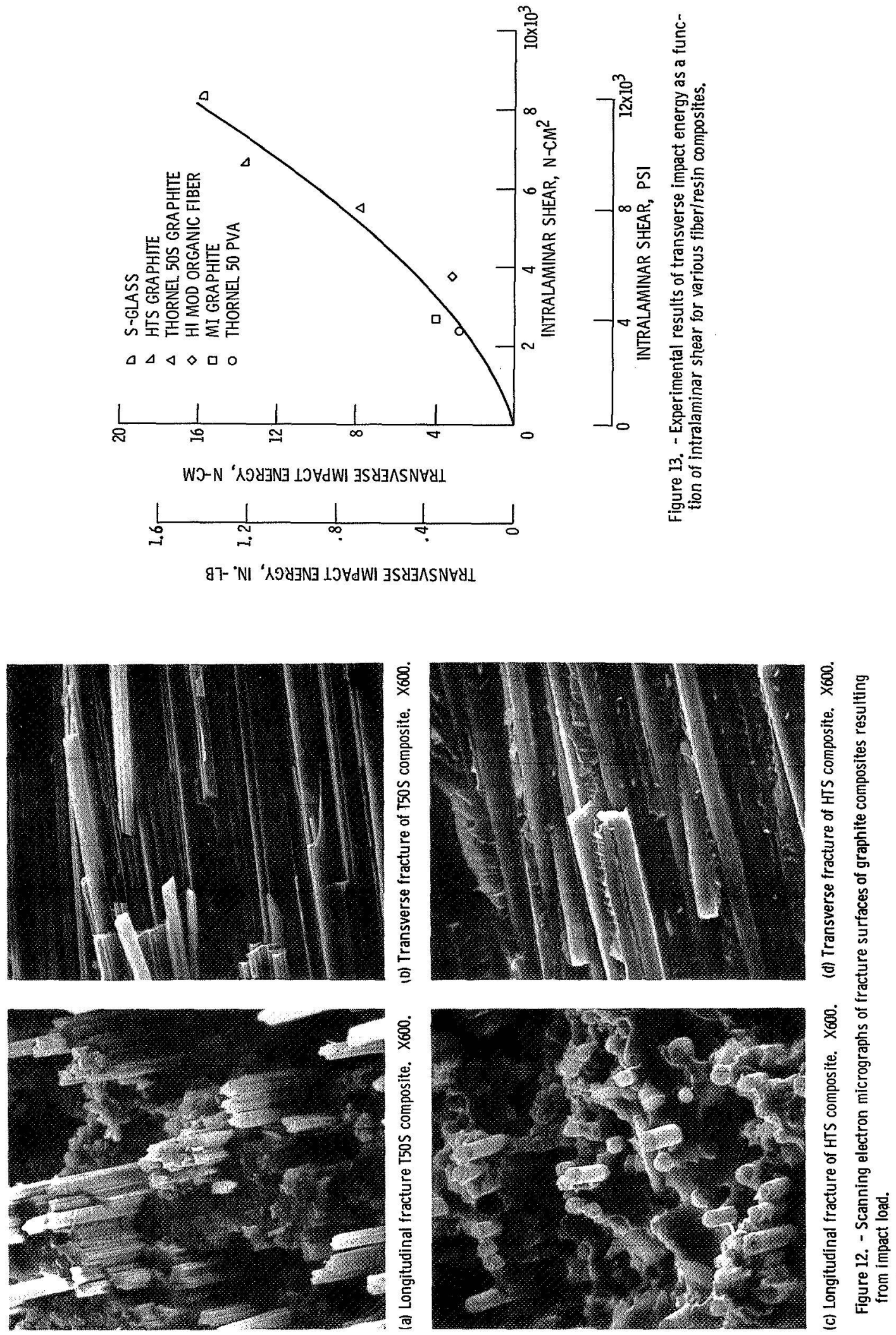

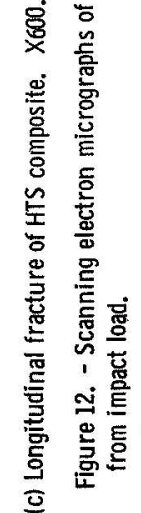

